26

\title{
Understanding the Effects of Past Flood Events and Perceived and Estimated Flood Risks on
}

Individuals' Voluntary Flood Insurance Purchase Behavior

.

4

(1)

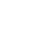

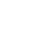

(

9

10

1

2

3

4

5

6

7

8

9

0

1

2

3

4

25

1

(C) 2016. This manuscript version is made available under the Elsevier user license http://www.elsevier.com/open-access/userlicense/1.0/ 
28 Wanyun Shao is an assistant professor in the Department of Sociology, Anthropology, and

29 Geography at Auburn University, Montgomery.

30

Siyuan Xian is a Ph.D candidate in the Department of Civil and Environmental Engineering at Princeton University.

Ning Lin is an assistant professor in the Department of Civil and Environmental Engineering at Princeton University

Howard Kunreuther is James G. Dinan Professor in the Wharton School at University of Pennsylvania

Nida Jackson is a graduate student in the Department of Sociology, Anthropology, and Geography at Auburn University, Montgomery

Kirby Goidel is a professor in the Department of Communication and a fellow in the Public Policy Research Institute at Texas A\&M University

W. Shao and S. Xian contributed equally to this work and are listed alphabetically 


\section{Abstract}

62 Over the past several decades, the economic damage from flooding in the coastal areas has greatly increased 63 due to rapid coastal development coupled with possible climate change impacts. One effective way to 64 mitigate excessive economic losses from flooding is to purchase flood insurance. Only a minority of coastal 65 residents however have taken this preventive measure. Using original survey data for all coastal counties of 66 the United States Gulf Coast merged with contextual data, this study examines the effects of external 67 influences and perceptions of flood-related risks on individuals' voluntary behaviors to purchase flood insurance. It is found that the estimated flood hazard conveyed through the U.S. Federal Emergency

69 Management Agency's (FEMA's) flood maps, the intensities and consequences of past storms and flooding 70 events, and perceived flood-related risks significantly affect individual's voluntary purchase of flood 71 insurance. This behavior is also influenced by home ownership, trust in local government, education, and 72 income. These findings have several important policy implications. First, FEMA's flood maps have been 73 effective in conveying local flood risks to coastal residents, and correspondingly influencing their decisions to 74 voluntarily seek flood insurance in the U.S. Gulf Coast. Flood maps therefore should be updated frequently to 75 reflect timely and accurate information about flood hazards. Second, policy makers should design strategies to 76 increase homeowners' trust in the local government, to better communicate flood risks with residents, to 77 address the affordability issue for the low-income, and better inform less educated homeowners through

78 various educational programs. Future studies should examine the voluntary flood insurance behavior across 79 countries that are vulnerable to flooding..

81 Key Words: Flood insurance purchase, flood risk, flood maps, risk communication, decision making. 


\section{Introduction}

Climate change is one of the most pressing issues facing society (IPCC, 2013). The coastal region is especially vulnerable to various adverse impacts of climate change such as rising sea level, increasing hurricane activity, more severe flooding, coastal erosion, and ocean acidification (Wong et al., 2014). To further complicate matters, there is a general trend of population movement to the coastal area. In the United States alone, more than 1.2 million people move to the coast annually, as a result of which more than half of the U.S. population (164 million) currently reside in densely populated coastal areas with concentrating development and enormous infrastructures (Moser et al., 2014). Coastal counties in the U.S. have witnessed a higher population increase ( 84.3 percent) than non-coastal counties $(64.3$ percent $)$ during the period of 1960-2008 (Wilson and Fischetti, 2010). There is some evidence that the coastal population growth is likely to continue in decades to come (NOAA, 2013).

The concentrations of coastal population and properties coupled with a changing climate have become one of the major contributors to a dramatic rise in economic losses incurred by natural hazards (Pielke et al. 2008; Estrada et al. 2015; Hallegate 2015). Among all natural hazards, flood is the most costly and has affected most people (Michel-Kerjan, 2015; Michel-Kerjan et al., 2015; Michel-Kerjan and Kousky, 2010; Perry, 2000). The number of Presidential Declarations associated with floods in the United States has risen substantially over the past 50 years (Kunreuther, 2015). Flood inundation poses enormous risks to human lives and structures, and causes substantial property damages (Hatzikyriakou et al., 2015; Perry, 2000). The hurricane-induced coastal flooding is predicted to be more frequent and intensive in many coastal megacities in the future (Lin and Emanuel, 2015; Lin et al., 2016).

Faced with the enormous threat posed by flooding, it would be sensible for people in flood-prone areas to undertake some preventative actions such as purchasing flood insurance. In reality, however, only a minority of coastal residents have flood insurance. Despite the insurance discount provided, participation rates in the National Flood Insurance Program (NFIP) are quite low (Petrolia et al., 2013). For instance, as 
many as 80 percent of the residents affected by flooding caused by Superstorm Sandy in 2012 had no flood insurance (Michel-Kerjan et al., 2015). Homeowners who live in a Special Flood Hazard Area ${ }^{1}$ (SFHA) are required to buy flood insurance if receiving mortgages from a federally backed or regulated lender in the U.S. However, some evidence suggests that this requirement is not strictly enforced (Dixon et al., 2006; Kriesel and Landry, 2004; Landry and Jahan-Parvar, 2011). The rate of compliance to the requirement is $75-80 \%$ in the U.S. (Dixon et al., 2006). Moreover, market penetration for flood insurance is not evenly distributed geographically. For instance, the average flood insurance take-up rate among all counties along the U.S. Gulf

114 Coast is 24.9 percent, with Aransas, Texas having the highest rate (81.28\%) and Mobile, Alabama the lowest rate $(2.53 \%)$ based on FEMA's insurance policy statistics by state (FEMA, 2016). The inadequate participation rate and uneven distribution of NFIP raise an essential question: what motivate people to 117 purchase flood insurance?

The Biggert-Waters Flood Insurance Reform, signed into law in 2012, aimed to price insurance premiums in the NFIP to reflect the actual risk. However, the implementation of this reform has been delayed due to the passage of Homeowner Flood Insurance Affordability Act of 2014. Policy makers' main concern is that the drastic increase in premium would further reduce individuals' motivation to purchase

122 insurance and raise the issue of affordability among many low-income homeowners. It is therefore important 123 for policy makers to understand individual's self-motivation to purchase flood insurance especially in cases 124 where having flood insurance is not mandatory. Such an understanding would provide policy makers with 125 insightful information that can be utilized to design specific policies that can motivate more homeowners to 126 buy flood insurance and accordingly increase participation rates especially when risk-based premium is 127 charged. This information may also be utilized to design effective subsidizing programs (Kousky and 128 Kunreuther, 2014) to address the affordability issue.

\footnotetext{
${ }^{1}$ SFHA refers to 100-year floodplain area where the mandatory purchase of flood insurance may apply; The SFHA includes various flood zones such as coastal flood hazard zones AE zone (subject to storm surge flooding) and VE zone (subject to storm surge and significant wave)
} 
Several studies have examined the factors that drove people to buy flood insurance. Some analyses

were based on aggregated data to understand the flood insurance demand and purchase at the county or state level (Atrya et al. 2015; Browne and Hoyt, 2000; Dixon et al. 2006). For example, Atrya et al. (2015) examined the effects of social factors and recent events on flood insurance take-up rates for counties in Georgia, U.S. Browne and Hoyt (2000) found a significant correlation between the state-level flood insurance purchases and flood loss of the state in the prior year. These studies revealed some important information at the aggregate level. However, the relationships at the aggregate level may not necessarily remain at the individual level (Gelman et al. 2009). Therefore, more studies based on individual-level data are needed. data, however, have typically focused on relatively small areas in different regions. Specifically, Michel-Kerjan and Kousky (2010) examined the variation among flood insurance buyers of different occupation types and the amount of insurance coverage based on policy-in-force data in Florida, U.S. Hung (2009) studied the attitudes of homeowners towards flood insurance purchase in Keelung River Basin of Taiwan. Brody et al. (2016) investigated the motivation to buy flood insurance outside the 100-year floodplain by focusing on four localities in Texas and Florida, US. Lo (2013) explored the relationship between having flood insurance and perceptions of social expectations in Brisbane, Australia. Oulahen (2014) conducted a case study in Metro Vancouver, Canada, to examine how attitudes toward flood insurance determined residential vulnerability to flood hazards. The local foci of these studies have led to some inconsistent conclusions as to what drives flood insurance purchase behavior. Studies based on larger data samples covering larger study areas and including more diverse populations are needed to further explore factors that influence flood insurance purchase behavior. Some scholars have attempted to encompass larger study areas. For instance, Petrolia et al. (2013) examined the relationships between risk perceptions and preferences on the one hand, and holding flood insurance policy on the other in the U.S. Gulf Coast and 
Florida's Atlantic Coast. This study found the significant effect of risk preferences on flood insurance 154 purchase. involvement in protecting society from natural hazards. In terms of flood insurance, it is particularly crucial

157 to understand the voluntary motivation of individuals' involvement. The recent efforts to reform the U.S. 158 NFIP and resistance to raising premiums to reflect actual risks make studies exploring determinants of 159 voluntary flood insurance purchase behavior even more timely and promising. Only a few studies, however, 160 have examined factors shaping the voluntary purchase of flood insurance. Among these studies, Lo (2013) 161 found that social norms played an essential role in determining voluntary adoption of flood insurance. Brody 162 et al. (2016) found that voluntary purchase decisions were positively associated with long-time residence, 163 higher value of homes, better education, perceptions of infrequent flood hazards and flood insurance 164 affordability. These studies, however, focused on one or two angles, e.g. social-demographic factors or flood 165 risk perception, without considering how the flood hazard estimated by policy makers would influence 166 individual voluntary behavior to purchase flood insurance. More studies are nevertheless needed to understand this voluntary purchase behavior. The influences 168 of social-demographic factors and perception of flood-related risk need to be further studied with a larger 169 data sample. Moreover, the surrounding environment consisting of both social and physical contexts has a 170 significant impact on individuals' behaviors (Stern, 2000). To illustrate, the vulnerability to flooding in one's 171 residence may heighten risk perceptions and correspondingly leads to proactive actions. Meanwhile, one's 172 flood insurance purchase behavior may influence others who reside in the same community.

173 Our study is the first to examine the relationship between socio-demographic characteristics, 174 individuals' perceived flood-related risks, objective measures of past flood events, and government's 175 estimated flood hazards, on the one hand, and the voluntary purchase of flood insurance, on the other. In 176 particular, our study is the first to examine whether flood hazards reflected in FEMA's flood maps can 177 influence individuals to purchase flood insurance voluntarily. The results will provide policy makers with 
178 insights into factors of coastal residents' voluntary behaviors to purchase flood insurance, which will 179 correspondingly help them design more effective strategies and mechanisms to communicate actual flood 180 risks with the public, and motivate them to mitigate economic losses from catastrophic floods in the future.

\section{2. Data and Methods}

The individual-level variables are constructed based on the 2012 Gulf Coast Climate Change Survey, which was designed to understand coastal residents' perceptions of local effects of climate change, and the residents' willingness to take personal actions and to support local climate policies to adapt to climate change in the U.S. Gulf Coast (Goidel et al., 2012). The survey utilized a stratified random sampling strategy drawing independent samples across and within states including Texas, Louisiana, Mississippi, Alabama,

187 and Florida. Data was collected by landline telephone from January 3 through April 4, 2012. The number of 188 respondents was 3856; the response rate in this survey was 17.6 percent. The objective data include surge 189 data from SURGEDATA (Needham and Keim, 2012), property damage data from Storm Events Database of 190 the National Climate Data Center (NCDC), and flood maps from FEMA. More details are provided in the 191 next section.

\section{2.1.Dependent Variables}

The two dependent variables are based on responses to two survey questions. The two questions are 194 "do you have flood insurance?" and "do you have flood insurance to feel safer or because it is required?" 195 FEMA requires homeowners who reside in the SFHA and receive mortgages from a lender that is federally 196 backed or regulated to purchase flood insurance. The lender requires borrowers (homeowners) to pay flood 197 insurance along with monthly mortgage payment.

To the first question, 48.7\% responded "Yes." and 48.8\% responded "No." and the rest replied

199 "Don't know." The percentage of respondents in the survey who have flood insurance per county is shown in 200 Fig. 1. The second question targeted those respondents who answered "Yes" to the first question and 
201 explored the reasons for their purchase of flood insurance. Three responses were provided for the second 202 question, "required." "safer." and "both." for the second question. The response "both" indicates that 203 residents buy flood insurance both because it is required and they want to feel safer. The percentage of 204 respondents in each category is shown in Fig. 2. Among the respondents who hold flood insurance, half 205 purchase flood insurance only to feel safer. The rest of the respondents with flood insurance are required to 206 buy (those who answered "required" or "both"). Among the people who are required to buy flood insurance, 207 half do so out of voluntary motivation to feel safer (those who answered "both"). Based on the information 208 provided by the two survey items, two dependent variables are created.

The first dependent variable includes two categories: people without flood insurance indicated by " 0. ." 210 and those who have flood insurance only because it makes them feel safer, represented by " 1 ." The behavior 211 of those who buy flood insurance to feel safer is purely voluntary because their purchase behavior was not 212 influenced by the requirement. Therefore, the first dependent variable differentiates homeowners without 213 flood insurance from those who buy flood insurance entirely out of voluntary motivation. In terms of the 214 second dependent variable, respondents who responded "safer" are combined with those who responded 215 "both" to the second question. "Both" indicates that the reasons for their flood insurance purchase are both 216 the requirement and their wish to feel safer. Different from the group of people who responded "safer", 217 people who responded "both" are required to buy flood insurance. However, this behavior is also driven by 218 some degree of voluntary motivation to protect themselves from flood loss. The second variable 219 differentiates those with no flood insurance from those who purchase flood insurance out of totally and 220 partially voluntary motivations altogether. The inclusion of the second dependent variable enables this study 221 to investigate whether the significance of explanatory factors in the series of models on the first dependent 222 variable remains when people who are partially driven by voluntary motivations are added. 
The individual-level independent variables, including socio-demographic features, home ownership, distance from the coast (self-reported), trust in the local government and flood-related risk perceptions, are

227 all constructed based on survey items. Table I demonstrates how these variables are coded and the

228 frequencies and percentages of each category within each variable. It should be noted that regression

229 diagnostics for multicollinearity are conducted among all the individual-level independent variables. None of

230 the variance inflation factors (VIFs) are sufficiently large to indicate that multicollinearity is a matter of 231 concern in our study.

The contextual variables include spatial information about flood hazards estimated by FEMA, peak height of storm surge from the most recent hurricane landfall, and economic damages from the most recent and most impacted flooding events, respectively. They are all at county-level. Flood hazards are indicated by the percentages of SFHA (100-year flood zones: A zones plus V zones) and high coastal flood risk VE zone per county, which are calculated based on FEMA's flood maps. The 100-year flood A and V zones refer to areas that would be inundated by a flood event with the chance of one percent every year. VE zones represent areas that are located in the proximity of the coast and are vulnerable to both storm surge induced 239 flooding and waves. Thus, the percentages of the SFHA and VE zone per county can indicate varying levels 240 of flood hazard across these coastal counties. The inclusion of contextual variables associated with the most recent hurricane landfall and flooding events is grounded on the theory of availability bias (Tversky \&

242 Kahneman, 1974). When judging risks and making decisions under uncertainty, humans are subject to 243 availability bias, referring to "situations in which people assess the frequency of a class or the probability of 244 an event by the ease with which instances or occurrences can be brought to mind."(Tversky \& Kahneman, 245 1974: 1127) The recent intensive events with high storm surge height and substantial economic damages are 246 supposedly easy for individuals to recollect. The objective variables as shown in Tables II-III are described 247 in detail as follows.

Storm surge from the latest hurricane landfall refers to the peak storm surge height from the latest hurricane landfall. The data are extracted from the updated version of SURGEDAT, which compiles data 
from 62 sources and identifies 195 storm surge events with the minimum height of 1.22 meters (Needham \&

251 Keim, 2012). Peak storm surge height indicates the relative severity of coastal flooding events. Percentage of 252 SFHA per county is defined as the ratio of the area of SFHA in a county to the total area of the county. The 253 variable is calculated based on the digital Flood Insurance Rate Map (FIRM) of FEMA in Geographical 254 Information System (GIS). Percentage of high risk VE zone per county is defined as the ratio of the area of 255 VE zone of a county to the total area of the county. This variable is also calculated by using the FEMA flood 256 maps. These two contextual variables related to flood zones represent varying coastal flood hazards 257 estimated by FEMA across counties. In addition to these two contextual variables, the individual-level 258 variable -distance from the coast can represent vulnerability to flood hazard at the building level. The 259 correlations between distance from the coast, and the two contextual variables related to flood hazard are 260 quite low, with 0.0095 (percentage of SFHA per county) and -0.0507 (percentage of high risk VE zone per county). Together with the distance from the coast, these contextual variables reflect varying levels of coastal flood risks. Maximum annual property damage from flooding in the last 10 years and annual property damage from the latest year when flooding occurred are two variables related to the consequences

264 of flooding events at the county level. These two variables are calculated using the Storm Events Database, an official database of the National Climate Data Center (NCDC). The annual property damage from

266 flooding is a cumulative measure over a year. The rationale of adopting a cumulative measure instead of a 267 single-even measure is as follows. Flood occurs more often than some other extreme weather events 268 such as hurricanes. Many small storms can generate flooding with small amounts of damages. People 269 may not be able to recall a particular flooding event with a small impact, but they may be left with 270 deeper impression about the cumulative impacts of frequent flooding events that happened in a 271 particular year. The selection of 10 years as the time frame for constructing the maximum annual property 272 damage from flooding is based on two considerations. First, people tend to have short memories. Any events 273 that occurred in the far distant past (e.g., over 20 years ago may be difficult for one to recall. Second, 274 drawing statistically meaningful trends out of a too short time period (e.g., 3 years) is difficult. Nevertheless, 
275 in addition to the timeframe of 10 years, 5- and 20-year timeframes are also tested in our study, but the 276 results are not sufficiently different from the 10-year timeframe, indicating that this measurement is not

277 sensitive to various timeframes. This study also includes the contextual variable of the County average

278 insurance premium to test the price elasticity of demand at the county level. It measures the responsiveness

279 of the demand for flood insurance to a change in its price. A previous study used the county-level insurance

280 premium and take-up rate to test price elasticity (Atreya et al., 2015).

\section{2.3. Methods}

The 2012 Gulf Coast Climate Change survey data provide state and county fips codes, allowing us to

283 merge the individual-level data with contextual data to develop mixed-effects logit regression models.

284 Merging individual-level and contextual data raises certain statistical complications, i.e. the error terms of 285 individual observations nested within the same county are no longer independent of one another. In addition, 286 to account for the unmeasured factors at the state level (e.g. state policies to address natural hazards, state 287 economic conditions, state building code, etc.) that may affect the adoption of flood insurance and are 288 correlated with the variables of interest, the state indicators need to be included in the models. Therefore, to 289 account for the multilevel data structure and avoid violating the fundamental assumption in regression 290 analysis, multi-level mixed-effects logit regression models (Hamilton, 2012) are employed in the study.

\section{3. Results and Discussions}

This study attempts to understand what factors drive residents to voluntarily purchase flood

293 insurance. Results of this study are especially important for policy makers to design effective communication 294 strategies and mechanisms to motivate the purchase of flood insurance among individuals who are not 295 currently required to buy flood insurance but are nevertheless exposed to varying levels of flood risks. 296 Moreover, understanding voluntary purchase of flood insurance is useful for policy makers to design 297 effective policy tools to increase the insurance market penetration in the reformed NFIP. 
Guided by this goal, the respondents are first classified into two groups and six models are estimated to explain the difference between these two groups, i.e., one without flood insurance and the other who buy flood insurance only because they want to feel safer (the flood insurance is not required for them). Model 1 of Table II, presents results of a two-level multilevel model with fixed effects of individual-level variables and random effects of states. Three out of the five socio-demographic variables stand out as significant

303 factors that explain individuals' voluntary decisions on flood insurance purchase. Compared to racial 304 minorities, white people are less likely to buy flood insurance voluntarily when controlling for the effects of 305 all other variables in this model. Numerous previous studies have demonstrated that racial minorities are more likely to perceive environmental risks and therefore express higher levels of concern due to their propensity to environmental distress (Finucane et al., 2000; Marshall, 2004; McCright and Dunlap, 2011b; Mohai and Bryant, 1998). The same interpretation can be applied here: white people are less likely than racial minorities to perceive flooding risks and therefore lack motivation to buy flood insurance voluntarily.

Another significant socio-demographic attribute is education. Individuals with higher levels of education tend to buy flood insurance for more safety. This fact indicates that higher level of education may

312 lead to better awareness of flood risks, which in turn positively affects one's voluntary decisions on flood 313 insurance purchase. Local policy makers may consider raising awareness of flood risks among residents 314 through various educational programs. Meanwhile, as expected, people with higher levels of income tend to 315 buy flood insurance to feel safer. Higher income is undoubtedly related to more resources that can be 316 allocated to prevent one from excessive loss to natural hazards. This result conveys an important message to 317 policy makers that affordability can cause substantial concern among low-income residents. According to the 318 theory of hierarchy of human needs (Maslow, 1943), humans tend to satisfy physiological needs such as food, 319 shelter, and economic stability before turning attention to other needs such as environmental quality and 320 self-actualization. Restricted by financial resources, low-income residents spend money on items necessary 321 for survival, and they have no additional money to invest in flood protection even if they perceive high risks. 322 Policy makers need to take this fact into consideration and design policies to assist low-income residents to 
323 be shielded from flood hazards. The voucher programs, designed to help those for whom insurance can be a

324 substantial economic burden, may be a feasible and effective solution for low-income homeowners (Kousky

$325 \&$ Kunreuther, 2014; Zhao et al., 2015). Vouchers can only be used to cover the portion of insurance

326 premium and costs of loans for hazard mitigation measures that exceed the economic limitations of

327 low-income homeowners. The voucher program would operate in parallel with risk-based insurance

328 premium pricing in the reformed NFIP (Kousky \& Kunreuther, 2014).

Furthermore, being an owner of a house increases one's probability of buying flood insurance voluntarily. Previous studies have found that homeowners may value their properties and thus are more compelled to prepare for tornadoes and floods than those who rent (Mulilis et al., 2000; Takao et al., 2004).

332 Our study reveals that homeownership affects voluntary flood insurance purchase behavior. The result 333 suggests that policies related to flood insurance in the reformed NFIP should be tailored to target both 334 homeowners and renters. To no one's surprise, the distance from the coast has a negative effect on 335 individuals' voluntary decision to buy flood insurance. People who live relatively far away from the coast 336 feel less vulnerable to flood impacts and choose not to buy flood insurance. This result is consistent with 337 some previous studies (Kriesel and Landry, 2004; Petrolia et al., 2013). In fact, a greater distance from the 338 coast nevertheless does not always reflect lower flood risks and therefore may mislead residents. In other 339 words, greater distance from the coast may bring a false sense of security. Local governments should inform 340 coastal residents of their actual flood risks. voluntarily. The US NFIP is administered by the partnership between FEMA and local governments.

343 Homeowners, especially those who are not required to buy flood insurance, need to have adequate trust in 344 the local government to deal with climate-related risks in order to feel comfortable of purchasing flood 345 insurance. This finding is in line with that of Atreya et al. (2015): those who lack trust in the local 346 government's competence have less voluntary willingness to buy flood insurance. This finding highlights the 
importance of building trust between the government and the governed. Local policy makers need to think of ways to earn more trust from residents to motivate them to actively seek flood protection measures.

Among all variables relating to environmental perceptions, beliefs in increasing flooding amount and hurricane strength exert positive impacts on voluntary decisions to buy flood insurance. Specifically, people who perceive that the amount of flooding has increased and that hurricanes have become stronger are more likely than others to buy flood insurance voluntarily. The connection between perceptions of increasing flooding amount and voluntary purchase of flood insurance is straightforward. Because hurricane strength is associated with storm surge flooding, the perception of increasing hurricane strength leads to a higher probability of voluntarily purchasing flood insurance. The results provide empirical evidence to support the relationship between risk perception and voluntary behavior, and urges policy makers to design effective risk communication tools to convey accurate flood risks to coastal residents.

The standardized coefficients of individual-level variables are also estimated to compare their contributing effects on the voluntary flood insurance purchase behavior. Standardized coefficients reveal that income is the most influential factor followed by homeownership and distance from the coast. This provides local policy makers with useful information on which they can prioritize specific policy strategies to motivate more residents to purchase flood insurance.

Models 2-7 of Table II demonstrate results of six multilevel models with six county-level contextual variables of flood risks, respectively. These variables include: peak storm surge height from the latest hurricane landfall, percentage of the area of SFHA per county, percentage of the area of high risk VE zone per county, annual maximum property damage from flooding in the last 10 years, annual property damage from the latest flooding event, and county average flood insurance premium. When estimating the effects of these six contextual variables, variables of flood-related risk perceptions are intentionally left out. The advantage of including contextual factors for studies of behaviors is that they are exogenous variables: the geographic context can cause flood insurance purchase behavior, but this behavior cannot change the context. 
371 Thus to determine if geographic context affects flood insurance purchase behavior, a very simple and valid

372 test is therefore a regression in which the behavior is predicted solely by contextual indicators. Control

373 variables are added to models if covariates are of concern, in cases where (1) these covariates may confound

374 the context-behavior relationship (2) but are not themselves caused by the context. Controls are ruled out if

375 they do not satisfy the second condition because in this estimation context they are "post-treatment" variables

376 that mediate the context-behavior relationship (Gelman and Hill, 2007; p. 188-190). Including post-treatment

377 variables as controls thus underestimate the magnitude of the effects of the context, because the estimates

378 represent only the contextual effects after removing any contextual effect that occurs through the mediators.

379 Perceptions of flood-related risks, and belief in climate change can be caused by the contextual factors (Shao,

380 2015; Shao et al., 2016; Shao \& Goidel, 2016), and thus they must be considered as mediators. Hence, we

381 estimate the effects of subjective risk perceptions of flooding and objective contextual flooding risks

382 separately.

Three contextual variables stand out as significantly positive factors in determining whether or not one chooses to buy flood insurance to feel safer. Specifically, residents in counties with higher peak storm

385 surge heights in the latest hurricane landfall, higher percentages of SFHA and high risk VE zone are more

386 likely than residents elsewhere to buy flood insurance to feel safer. For those who buy flood insurance totally

387 voluntarily, the memory of the destructive power associated with the last peak storm surge may be vivid.

388 This result suggests that peak storm surges with higher intensity are more likely to evoke stronger emotions

389 and leave longer impressions. These high-impact events are therefore more retrievable in one's mind as a

390 previous study found (Shao et al., 2016). In addition to all the contextual variables presented in the paper, the

391 effect of 10-year trends of the annual number of floods is also tested but turns out to be insignificant. The

392 significant effect of storm surge from the latest hurricane landfall combined with the insignificant impact of

393 trend of floods further reinforces the availability bias.

394 The statistically significant results about percentage of SFHA and high risk VE zone per county

395 illustrate that FEMA's flood maps may have been effective in conveying the relative coastal flooding 
hazards to residents in different possible ways. First, people may view the flood map themselves through the Floodsmart.gov website or FEMA website to determine the flood risk of their property and their surrounding environment when deciding to purchase flood insurance. Second, FEMA and the local government are in partnership about informing local residents of their flood risks through education programs, community meetings, and personal communications with local officials. For example, one of the authors in this study had an opportunity to interview a city hydrologist in the city of Huntsville, Alabama in September, 2016.

402 The hydrologist stressed his frequent role of persuading homeowners who live in the proximity of SFHA to 403 purchase flood insurance even they are not required to do so by showing them FEMA's flood maps. Third, 404 the flood hazards in flood maps can be indirectly conveyed through the behavior of the people living close 405 by, e.g., neighbors. In our study, we found that the contextual flood hazard conveyed through the flood map 406 is correlated with the flood insurance take-up rate at the county-level (a correlation of 0.52), and the take-up 407 rate is also statistically significant to voluntary purchase of flood insurance. This finding suggests that it is possible that the perception of flood hazards through flood maps may indirectly influences people's behavior. Overall, FEMA's flood maps have the capacity of influencing voluntary flood insurance purchase behaviors.

410 Individuals living in counties with higher percentages of flood hazard zones estimated by FEMA are more 411 likely to buy flood insurance to feel safer than those living in counties with lower percentages of flood 412 hazard regions. FEMA's flood maps serve as an important risk communication tool for coastal residents, and 413 further affect their decisions on voluntary purchase of flood insurance.

On the other hand, serious issues arise in cases where FEMA flood maps do not reflect flood risks accurately or properly. FEMA flood maps can provide misleading information to coastal residents, resulting in less ideal decisions on flood protection. For instance, people who live on slightly higher grounds but very 417 close to the coast may have a false sense of safety because FEMA often designates such locations as low 418 flood risk zones. However, they are subject to heavy coastal flooding and wave hazards due to the proximity 419 to the sea (Xian et al., 2015). Some previous studies have also raised potential issues with using relatively 420 low-resolution FEMA flood maps for local risk assessments (Czajkowski et al., 2013). FEMA's flood maps 
421 need to consider the detailed distribution of hazards, and be updated more frequently with more accurate and

422 timely projections of storm characteristics and improved hydraulic and wave modeling (Crowell et al., 2007;

423 Czajkowski et al., 2013; Shan et al., 2009; Xian et al., 2015). Therefore, policy makers should exercise

424 caution when using the FEMA flood map to communicate the actual risks to the public.

Annual maximum property damage from flooding in the last 10 years ( 5 and 20 years are also tested

426 and none of them are statistically significant) and annual property damage flooding in the latest year do not

427 appear to have any significant effects on one's decision to buy flood insurance voluntarily. One possible

428 reason for this finding is that these two county-level measures of property damages from flooding provide

429 only aggregate information of economic losses county wide. Aggregate damage may not necessarily reflect

430 individual personal property damages, and thus have limited influence affecting personal voluntary flood

431 insurance behavior.

The insignificance of average flood insurance premiums at the county-level reveals some degrees of price inelasticity of demand for flood insurance, which is consistent from previous study (Atreya et al., 2015).

434 On the contrary, we found a positive income effect at the individual level, as discussed before.

This study attempts to identify the factors that motivate voluntary behaviors. Therefore, the group of individuals who buy flood insurance out of a combination of voluntary and mandatory reasons cannot be

437 ignored. Accordingly, the respondents are classified into two groups based on the survey questions, i.e., 438 individuals without flood insurance and those with flood insurance because they want to feel safer regardless 439 of the requirement. Individuals who buy flood insurances only to feel safer are combined with those who buy 440 insurance both because they want to feel safer and the flood insurance is required to them, and this combined 441 group is compared with individuals who have no flood insurance. As shown in Table III, the results are 442 similar to those revealed in the models of Table II. First, racial minorities and individuals with higher 443 education and more income are more likely than their counterparts to buy flood insurance. Homeowners and 444 people who live near the coast and have more trust in the local government are more inclined to buy flood 
insurance. Perceptions of changing flooding amount and hurricane strength are found to be positively related to the choice to purchase flood insurance.

Among the contextual forces, percentages of the area of SFHA and coastal high risk VE zone per county remain to be strong factors in determining voluntary purchase of flood insurance. The major difference is that peak storm surge from the last landfall hurricane appears not to be significant in Table III. This difference can be explained by the fact that flood insurance buyers who act out pure voluntary motivation tend to assign a heavier weight to the latest intensive flooding experience when deciding to purchase flood insurance compared to those partially voluntary flood insurance holders. In other words, the most recent intense flood event may lead some individuals to live in fear which compels them to buy flood insurance just to "feel safer".

\section{Conclusions}

The economic damage from coastal flooding has been dramatically growing in recent decades due to the combination of massive population movement to the coastal zone and climate change effects. The U.S.

458 NFIP has been in billions of debt to the Treasury Department since Hurricane Katrina. The Biggert-Waters 459 Act of 2012 aimed to solve the problem of NFIP's insolvency but has met with strong resistances among 460 coastal residents. The flood insurance market penetration is relatively low and far from being universal 461 across coastal counties. A substantial number of people facing high flood risks do not hold flood insurance 462 (Dixon et al., 2006). Against this backdrop, it is imperative to understand coastal residents' voluntary flood 463 insurance purchase behaviors to help policy makers reform the NFIP to make it more effective and efficient. 464 This study attempts to investigate factors that drive individuals' voluntary purchase of flood insurance by 465 using survey data for coastal counties along the entire U.S. Gulf Coast. Results of this study reveal some 466 relationships between some socio-demographic attributes and perceived and estimated flooding risks, on the 467 one hand, and voluntary flood insurance purchase behavior, on the other. Specifically, four main findings 468 arise, and the associated implications are discussed. 
First, racial minorities are more likely to buy flood insurance voluntarily. This finding can be

470 interpreted in the light of existing literature on race and environmental risk perceptions. Racial minorities,

471 due to the excessive burden of environmental distress (Mohai and Bryant, 1998), tend to perceive

472 environmental risks (Finucan et al., 2000; Marshall, 2004) and express more concern for these risks

473 (McCright and Dunlap, 2010). These heightened risk perceptions may influence voluntary behaviors to

474 mitigate risks, as shown in our study. As expected, individuals with more income are more likely to buy

475 insurance regardless of the requirement. Another important finding about the socio-demographic

476 characteristics is the significant effects of education in determining one's voluntary choice to buy flood

477 insurance. The interpretation can be that better education leads to a higher level of awareness and better

478 knowledge of flood risks, which correspondingly can translate into behaviors to mitigate these risks. These

479 results highlight the importance of informing coastal residents of their flood risks especially among those

480 less educated homeowners. This can be achieved by FEMA in partnership with local policy makers through

481 educational programs and other forms of community engagement.

Second, perceptions of flooding amount, and hurricane strength shifts over the recent past are

483 found to have positive effects on voluntary purchase of flood insurance. Coastal residents who perceive

484 increasing trends of flooding amount and hurricane strength are more likely to hold flood insurance to feel

485 safer. The results provide empirical evidence that heightened perceptions of flood-related hazards can

486 motivate people to proactively seek protection measures. Policy makers should explore approaches to

487 provide scientific information on these flood-related hazards.

Third, the other two individual-level variables that are significantly associated with voluntary

489 purchase of flood insurance are: self-reported distance from the coast and belief in the local government's

490 preparedness to address climate change. As expected, with the increase of distance from the coast, the

491 probability of voluntarily purchasing flood insurance decreases. Greater distance from the coast nevertheless

492 does not always mean lower flood risks, and therefore can give residents a false sense of safety. This finding

493 suggests that local policy makers should inform and educate coastal residents about their actual flood risks. 
494 Meanwhile, individuals' trust in local governments' preparedness to address climate change can lead to

495 voluntary purchase of flood insurance. This finding implies that coastal residents rely on the local

496 government to mitigate flooding hazards. It also highlights the importance of the trust between the local

497 government and residents.

Fourth, the most important finding of this study is the significant impact of contextual forces. The positive effect of peak storm surge from the last hurricane landfall confirms the theory of availability bias. These characteristics of intensive and recent storm surge flooding event present some mental ease with which individual accesses and retrieves past information compared to the trend of storm surge intensity (Shao et al. 2016). More importantly, percentages of the areas of SFHA and high-risk VE zones per county affects voluntary flood insurance behavior. These contextual forces of flood risks conveyed through FEMA's flood maps can motivate individuals to buy flood insurance to feel safer even when they are not required to.

This significant finding about the flood zones designated by FEMA sends both positive and negative messages to policy makers. From a positive perspective, FEMA has been successful, at least as shown in the Gulf Coast, in conveying varying county-level flooding risks to coastal residents via their maps. On the other hand, some previous studies have demonstrated that FEMA's maps may not be accurate and hence can send 509 misleading signals to coastal residents (Shan et al., 2009; Czajkowski et al., 2013; Xian et al., 2015). FEMA 510 therefore needs to update its maps more frequently and apply the best available methods to reflect the real 511 flood risks in a timely fashion.

The research agenda on individuals' flood insurance purchase behaviors is far from complete. First, 513 many questions related to the flood insurance behavior remain to be addressed. For example, what factors 514 would determine the amount of insurance coverage and the amount of deductible that homeowners are 515 willing to take? Second, some scholars have proposed feasible solutions to NFIP's insolvency and 516 individuals' affordability issues (Kunreuther, 2016; Kunreuther and Michel-Kerjan, 2009; Kousky and 517 Kunreuther, 2014; Zhao et al., 2015). Vouchers are proposed to target low-income homeowners who cannot 518 afford risk-based insurance premium (Kousky and Kunreuther, 2014). The voucher program would operate 
519 in parallel with risk-based insurance pricing to solve the NFIP's insolvency. More studies are needed to test

520 whether the proposed policy solution would be feasible and acceptable among low-income coastal residents

521 and local officials. Third, tailored studies are needed to examine how exactly coastal residents perceive

522 FEMA's flood maps and other governmental tools that aim to reflect flood risks (e.g. flood return period,

523 probability distribution of flood levels or probability of flooding over a certain period). Fourth, the important

524 information that needs to be communicated with residents in flood-prone areas include: the likelihood of

525 future floods, the potential damages these floods will incur, and insurance premiums calculated based on real

526 risks under the contexts of climate change and sea level rise. Future studies should aim to assist policy

527 makers in designing more effective risk communication tools to convey the state-of-the-art risk information

528 to members of flood-prone communities. Fifth, with increasing flood risks in the future, flood insurance can

529 be an effective way to protect homeowners from significant flood losses. Understanding voluntary

530 motivations in flood insurance purchase is crucial in other countries that are also vulnerable to flooding but

531 lack national flood insurance programs and enforced requirements such as Netherlands, Vietnam, China, etc.

532 More studies exploring determinants of flood insurance purchase behavior in other countries should be

533 invited.

\section{Acknowledgements}

536 We would like to thank LaDonn Swann, Tracy Sempier, and Melissa Schneider for their support in 537 designing and implementing the 2012 Gulf Coast Climate Change Survey. The survey research 538 included in the analysis was supported by the U.S. Department of Commerce's National Oceanic 539 and Atmospheric Administration's Gulf of Mexico Coastal Storm Program under NOAA Award 540 NA10OAR4170078, Texas Sea Grant, Louisiana Sea Grant, Florida Sea Grant, and

541 Mississippi-Alabama Sea Grant Consortium. The views expressed herein do necessarily reflect the 542 views of any of these organizations. Neither the organizations nor the individuals named above bear 
543 any responsibility for any remaining errors. S. Xian and N. Lin are supported by National Science 544 Foundation (NSF) grant: EAR-1520683. 


\section{REFERENCE}

Aerts, J. C., Botzen, W., Emanuel, K., Lin, N., Moel, H., \& Michel-Kerjan, E. O. (2014). Evaluating flood resilience strategies for coastal megacities. Science, 344(6183), 473-475.

Aerts, J. C., Lin, N., Botzen, W., Emanuel, K., \& de Moel, H. (2013). Low-probability flood risk modeling for New York City. Risk Analysis, 33(5), 772-788. doi: 10.1111/risa.12008.

Atreya, A., Ferreira, S., \& Michel-Kerjan, E. (2015). What drives households to buy flood insurance? New evidence from Georgia. Ecological Economics, 117, 153-161.

Brody, S. D., Highfield, W. E., Wilson, M., Lindell, M. K., \& Blessing, R. (2016). Understanding the motivations of coastal residents to voluntarily purchase federal flood insurance. Journal of Risk Research. doi:10.1080/13669877.2015.1119179.

Browne, M. J., \& Hoyt, R. E. (2000). The demand for flood insurance: Empirical evidence. Joumal of Risk and Uncertainty, 20(3), 291-306.

Crowell, M., Hirsch, E., \& Hayes, T. L. (2007). Improving FEMA's coastal risk assessment through the National Flood Insurance Program: an historical overview. Marine Technology Society Journal, 41(1), 18-27.

Czajkowski, J., Kunreuther, H., \& Michel-Kerjan, E. (2013). Quantifying Riverine and Storm-Surge Flood Risk by Single-Family Residence: Application to Texas. Risk Analysis, 33(12), 2092-2110.

Dietz, T., Dan, A., \& Shwom, R. (2007). Support for climate change policy: Social psychological and social structural influences. Rural Sociology, 72(2), 185-214. Retrieved from $<$ Go to ISI $>$ ://000246939400002.

Dixon, L., Clancy, N., Seabury, S. A., \& Overton, A. (2006). The National Flood Insurance Program's market penetration rate: estimates and policy implications. Santa Monica, CA: RAND Corporation. Retrieved from:

http://biotech.law.lsu.edu/disasters/insurance/nfip_eval_market_penetration_rate.pdf Accessed Oct 2, 2016.

Estrada, F., Botzen, W. W., \& Tol, R. S. (2015). Economic losses from US hurricanes consistent with an influence from climate change. Nature Geoscience. 8, 880-884. doi:10.1038/ngeo2560.

Federal Emergency Management Agency (2016). Policy Information by State (As of April, 2016). FEMA, Washington, DC. Data Retrieve from:

https://bsa.nfipstat.fema.gov/reports/1011.htm Accessed April 12th, 2016 
Finucane, M. L., Slovic, P., Mertz, C. K., Flynn, J., \& Satterfield, T. A. (2000). Gender, race, and perceived risk: the 'white male' effect. Health Risk \& Society, 2(2), 159-172. Retrieved from $<$ Go to ISI $>$ ://000088768700003.

Gelman A, Hill J (2007) Data Analysis Using Regression and Hierarchical/Multilevel

Models. $1^{\text {st }}$ Edition. New York: Cambridge University Press.

Gelman, A. (2009). Red state, blue state, rich state, poor state: Why Americans vote the way they do. $2^{\text {nd }}$ Edition. Princeton: Princeton University Press.

Goidel, K., Kenny, C., Climek, M., Means, M., Swann, L., Sempier, T., \& Schneider, M. (2012). 2012 Gulf Coast Climate Change Survey. Retrieved from:

http://www.southernclimate.org/documents/resources/Climate_change_perception_survey_su mmary_NOAA_Sea_Grant_2012.pdf Accessed Oct 2, 2016

Hallegatte, S. (2015). Climate change: Unattributed hurricane damage. Nature Geoscience, 8(11), 819-820.

Hamilton, L. (2012). Statistics with Stata. Belmont, CA: Cengage Learning.

Hatzikyriakou, A., Lin, N., Gong, J., Xian, S., Hu, X., \& Kennedy, A. (2015).

Component-Based Vulnerability Analysis for Residential Structures Subjected to Storm Surge Impact from Hurricane Sandy. Natural Hazards Review, 05015005.

Hung, H. C. (2009). The attitude towards flood insurance purchase when respondents' preferences are uncertain: a fuzzy approach. Journal of Risk Research, 12(2), 239-258.

IPCC. (2013). Climate change 2013: the physical science basis. Retrieved from Cambridge, United Kingdom and New York, NY, USA.

Jaeger, C., Durrenberger, G., Kastenholz, H., \& Truffer, B. (1993). Determinants of environmental action with regard to climate change. Climatic Change, 23(3), 193-211. doi:10.1007/bf01091615

Keim, B. D., \& Muller, R. A. (2009). Hurricane of the Gulf of Mexico. LA: Baton Rouge: Louisiana State University Press.

Kousky, C. (2011). Understanding the demand for flood insurance. Natural Hazards Review, 12(2), 96-110. doi:10.1061/(ASCE)NH.1527-6996.0000025

Kousky, C., \& Kunreuther, H. (2014). Addressing Affordability in the National Flood Insurance Program. Journal of Extreme Events, 1(01), 1450001. 
Kriesel, W., \& Landry, C. (2004). Participation in the National Flood Insurance Program: An empirical analysis for coastal properties. Journal of Risk and Insurance, 71(3), 405-420.

Kunreuther, H. (2015). The role of insurance in reducing losses from extreme events: the need for public-private parterships. The Geneva Papers, 40, 741-762.

Kunreuther, H., \& Slovic, P. (1978). Economics, psychology, and protective behavior. The American Economic Review, 68(2), 64-69.

Kunreuther, H. (2016). Reducing losses from catastrophes: role of insurance and other policy tools. Environment: Science and Policy for Sustainable Development, 58(1), 30-37.

Kunreuther, H., \& Michel-Kerjan, E. (2009). At war with the weather. MA: Cambridge: MIT Press.

Landry, C. E., \& Jahan-Parvar, M. R. (2011). Flood insurance coverage in the coastal zone. Journal of Risk and Insurance, 78(2), 361-388.

Lin, N., \& Emanuel, K. (2015). Grey swan tropical cyclones. Nature Climate Change, 6(1), 106-111.

Lin, N., Kopp, R.E., Horton, B.P. and Donnelly, J.P. (2016). Hurricane Sandy’s flood frequency increasing from year 1900 to 2100. Proceedings of the National Academy of Sciences. doi/10.1073/pnas. 1604386113.

Lo, A. Y. (2013). The likelihood of having flood insurance increases with social expectations. Area, 45(1), 70-76.

Lo, A. Y. (2013). The role of social norms in climate adaptation: Mediating risk perception and flood insurance purchase. Global environmental change, 23(5), 1249-1257.

Marshall, B. K. (2004). Gender, race, and perceived environmental risk: The "white male" effect in cancer alley, La. Sociological Spectrum, 24(4), 453-478. doi:10.1080/02732170490459485

Maslow, A. H. (1943). A theory of human motivation. Psychological Review, 50, 370-396. doi: $10.1037 / \mathrm{h} 0054346$

McCright, A. M., \& Dunlap, R. E. (2011b). Cool dudes: The denial of climate change among conservative white males in the United States. Global Environmental Change-Human and Policy Dimensions, 21(4), 1163-1172. doi:10.1016/j.gloenvcha.2011.06.003

Michel-Kerjan, E. O. (2015). We must build resilience into our communities. Nature, 524, 389. 
Michel-Kerjan, E. O., Botzen, W., Kunreuther, H., Atreya, A., Campbell, K., Collier, B., Czajkowski, J., \& Montgomery, M. (2015). Why many individuals still lack flood protection: new findings. Zurich Insurance Company. Retrieved from

http://opim.wharton.upenn.edu/risk/library//ZAlliance-why-individuals-lack-flood-protection _IB2015.pdf Accessed Oct 2, 2016

Michel-Kerjan, E. O., \& Kousky, C. (2010). Come rain or shine: evidence on flood insurance purchases in Florida. The Journal of Risk and Insurance, 77(2), 369-397.

Mohai, P., \& Bryant, B. (1998). Is there a "race" effect on concern for environmental quality? Public Opinion Quarterly, 62(4), 475-505. doi:10.1086/297858

Moser, S. C., Davidson, M. A., Kirshen, P., Mulvaney, P., Murley, J. F., Neumann, J. E., ... \& Reed, D. (2014). Coastal zone development and ecosystems. JM Melillo, TC Richmond, and GW Yohe, editors. Climate change impacts in the United States: The Third National Climate Assessment. US Global Change Research Program, Washington, DC, USA, 579-618.

Mulilis, J.-P., Duval, T. S. and Bovalino, K. (2000) Tornado preparedness of students, nonstudent renters, and nonstudent owners: issues of PrE Theory, Journal of Applied Social Psychology 30(6), 1310-29.

Needham, H. F., \& Keim, B. D. (2012). A storm surge database for the US Gulf Coast. International Journal of Climatology, 32, 2108-2123. doi:10.1002/joc.2425

NOAA. (2013). NOAA, U.S. Census report finds increases in coastal population growth by 2020 likely, putting more people at risk of extreme weather. Retrieved from:

http://www.noaanews.noaa.gov/stories2013/20130325_coastalpopulation.html Accessed Oct 2,2016

O'Connor, R. E., Bord, R. J., \& Fisher, A. (1999). Risk perceptions, general environmental beliefs, and willingness to address climate change. Risk Analysis, 19(3), 461-471.

Oulahen, G. (2015). Flood insurance in Canada: Implications for flood management and residential vulnerability to flood hazards. Environmental Management 55(3), 603-615.

Perry, C. A. (2000). Significant floods in the United States during the 20th century-USGS measures a century of floods, US Geological Survey, Fact Sheet 024-00, March 2000. Retrieved from: https://pubs.er.usgs.gov/publication/fs02400 Accessed Oct 2, 2016

Petrolia, D. R., Landry, C. E., \& Coble, K. H. (2013). Risk preferences, risk perceptions, and flood insurance. Land Economics, 89(2), 227-245. 
Pielke, Jr., R. A., Gratz, J., Landsea, C. W., Collins, D., Saunders, M. A., and Musulin, R. (2008). Normalized Hurricane Damages in the United States: 1900-2005. Natural Hazards Review, 9(1), 29-42.

Semenza, J. C., Hall, D. E., Wilson, D. J., Bontempo, B. D., Sailor, D. J., \& George, L. A. (2008). Public Perception of Climate Change Voluntary Mitigation and Barriers to Behavior Change. American Journal of Preventive Medicine, 35(5), 479-487. doi:10.1016/j.amepre.2008.08.020

Shan, J., Hussain, E., Kim, K., \& Biehl, L. (2009). Flood Mapping and Damage Assessment-A Case Study in the State of Indiana Geospatial Technology for Earth Observation, pp 473-495, Springer, US.

Stern, P. C. (2000). Toward a coherent theory of environmentally significant behavior. Journal of Social Issues, 56(3), 407-424. doi:10.1111/0022-4537.00175

Shao, W. (2015). Are actual weather and perceived weather the same? - understanding perceptions of local weather and their effects on risk perceptions of global warming. Journal of Risk Research. 19(6), 1-21. doi:10.1080/13669877.2014.1003956

Shao, W., \& Goidel, K. (2016). Seeing is believing? - An examination of perceptions of local weather conditions and climate change among residents in the U.S. Gulf Coast. . Risk Analysis. doi:10.1111/risa.12571

Shao, W., Xian, S., Keim, B. D., Goidel, K., \& Lin, N. (2016). Understanding perceptions of changing hurricane strength along the US Gulf coast. International Journal of Climatology. doi:10.1002/joc. 4805

Takao, K., Motoyoshi, T., Sato, T., Fukuzondo, T., Seo, K., \& Ikeda, S. (2004). Factors determining residents' preparedness for floods in modern megalopolises: the case of the Tokai flood disaster in Japan. Journal of Risk Research, 7(7-8), 775-787.

Tversky, A., and Kahneman, D. (1974). Judgment under uncertainty: heuristics and biases. Science, 185 (4157), 1124-1131.

Wilson, S. G., \& Fischetti, T. R. (2010). Coastline population trends in the United States: 1960 to 2008. US Department of Commerce, Economics and Statistics Administration, US Census Bureau, Washington. http://www.census.gov/prod/2010pubs/p25-1139.pdf Accessed Oct 2, 2016

Wong, P. P., Losada, I. J., Gattuso, J.-P., Hinkel, J., Khattabi, A., Mclnnes, K. L., Saito, Y., \& Sallenger, A. (2014). Coastal systems and low-lying area. Retrieved from Cambridge, United Kingdom and New York, NY, USA: 
Xian, S., Lin, N., \& Hatzikyriakou, A. (2015). Storm surge damage to residential areas: a quantitative analysis for Hurricane Sandy in comparison with FEMA flood map. Natural Hazards, 79(3), 1867-1888.

Zahran, S., Brody, S. D., Grover, H., \& Vedlitz, A. (2006). Climate change vulnerability and policy support. Society \& Natural Resources, 19(9), 771-789.

doi:10.1080/08941920600835528

Zhao, W., Kunreuther, H \& Czajkowski, J. (2015). Affordability of the National Flood Insurance Program: application to Charleston county, South Carolina. Natural Hazards Review, 17 (1). 10.1061/(ASCE)NH.1527-6996.0000201, 04015020. 


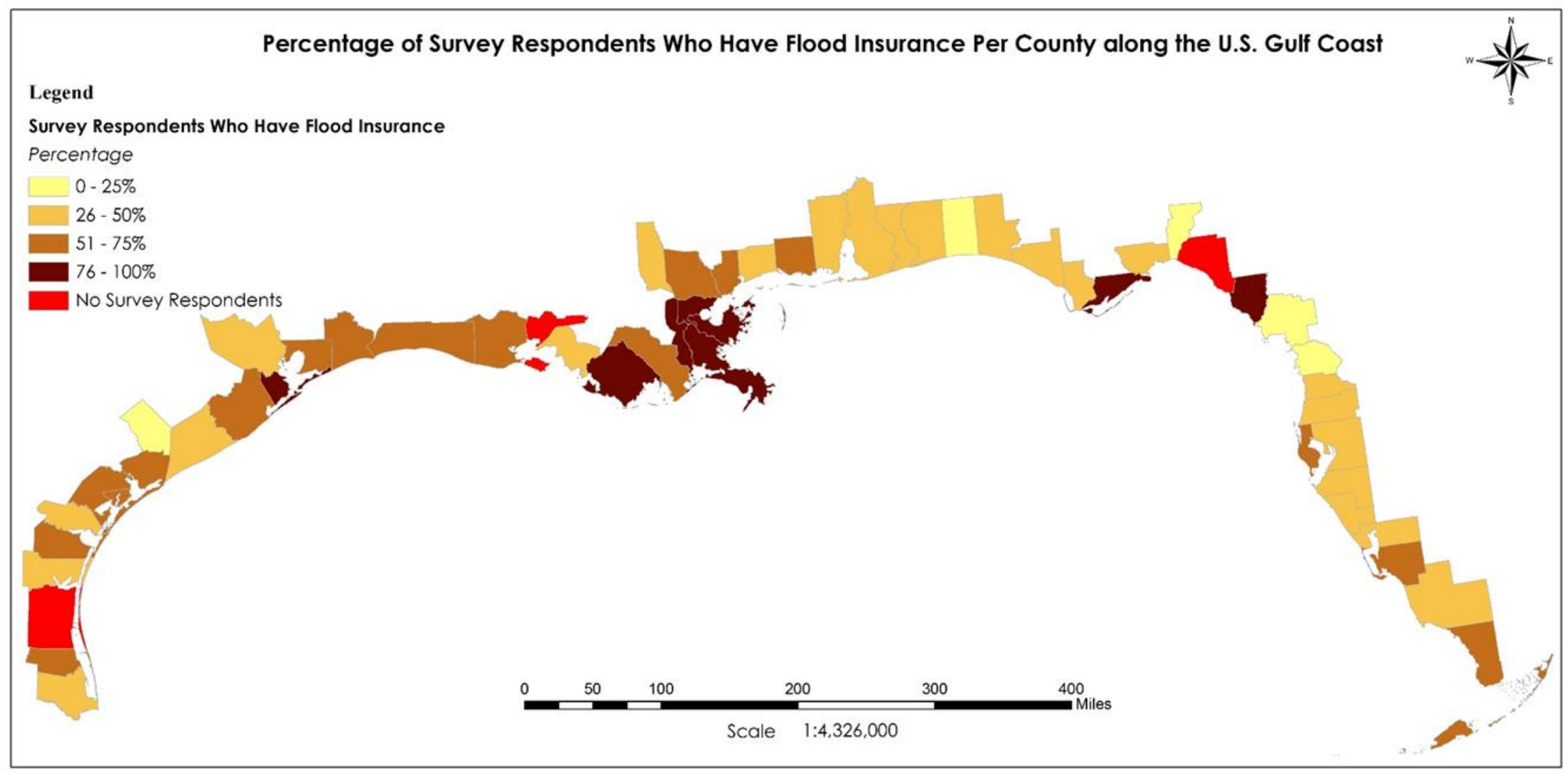

Figure 1. The spatial distribution of percentage of survey respondents who have flood insurance per county along the U.S. Gulf Coast 


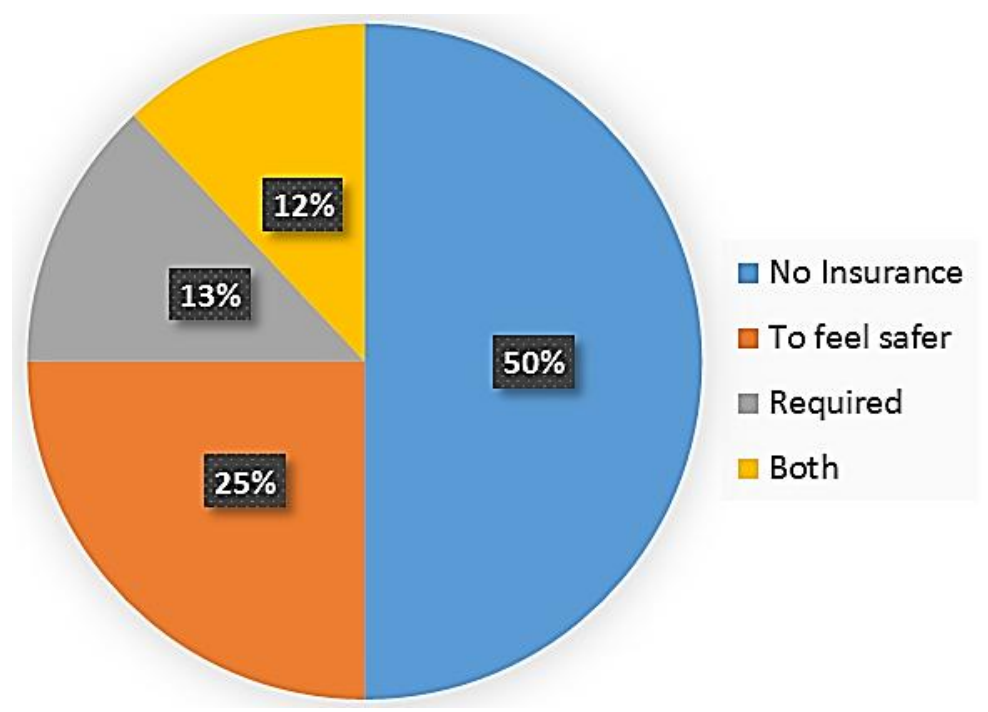

Figure 2. Proportion of respondents in each flood insurance category (i.e. 1. Without insurance; 2 . They buy insurance only to feel safer; 3 . They buy insurance as they know that they are required; 4 . They buy insurance both because to feel safer and they know they are required) 
Table I. Individual-level independent variables

\begin{tabular}{|c|c|c|c|}
\hline Individual-level Independent Variables & Code & Frequency & Percent (\%) \\
\hline \multicolumn{4}{|l|}{ Socio-demographic } \\
\hline \multicolumn{4}{|l|}{ Age } \\
\hline $18-24$ & 1 & 79 & 2.0 \\
\hline $25-34$ & 2 & 205 & 5.3 \\
\hline $35-44$ & 3 & 393 & 10.2 \\
\hline $45-54$ & 4 & 733 & 19.0 \\
\hline $55-64$ & 5 & 981 & 25.4 \\
\hline 65 and over & 6 & 1431 & 37.1 \\
\hline \multicolumn{4}{|l|}{ Gender } \\
\hline Female & 1 & 2305 & 59.8 \\
\hline Male & 0 & 1551 & 40.2 \\
\hline \multicolumn{4}{|l|}{ Race } \\
\hline White & 1 & 2797 & 72.5 \\
\hline Others & 0 & 1055 & 27.4 \\
\hline \multicolumn{4}{|l|}{ Education } \\
\hline Less than $\mathrm{HS}$ & 1 & 220 & 5.7 \\
\hline HS Degrees & 2 & 770 & 20.0 \\
\hline Some College & 3 & 1214 & 31.5 \\
\hline College Degree & 4 & 1609 & 41.7 \\
\hline \multicolumn{4}{|l|}{ Income } \\
\hline Under $\$ 10,000$ & 1 & 186 & 4.8 \\
\hline$\$ 10,000-\$ 19,999$ & 2 & 255 & 6.6 \\
\hline$\$ 20,000-\$ 29,999$ & 3 & 292 & 7.6 \\
\hline$\$ 30,000-\$ 39,999$ & 4 & 273 & 7.1 \\
\hline$\$ 40,000-\$ 49,999$ & 5 & 255 & 6.6 \\
\hline$\$ 50,000-\$ 74,999$ & 6 & 506 & 13.1 \\
\hline$\$ 75,000-\$ 99,999$ & 7 & 434 & 11.3 \\
\hline$\$ 100,000$ or more & 8 & 653 & 16.9 \\
\hline \multicolumn{4}{|l|}{ Partisanship } \\
\hline Democrat & -1 & 1100 & 28.5 \\
\hline Independent & 0 & 1232 & 32.0 \\
\hline Republican & 1 & 1246 & 32.3 \\
\hline \multicolumn{4}{|l|}{ Home Ownership (Dummy Variables) } \\
\hline Own & & 3191 & 82.8 \\
\hline Rent & & 447 & 11.6 \\
\hline
\end{tabular}

Distance from the coast 
Adjacent/On the water

Near the water/within 1 - 2 miles

Within 2 - 5 miles

5 - 10 miles

Trust in Local Government's Preparedness to Address Climate Change Issues

$$
\text { Not prepared at all }
$$

Not very prepared

Somewhat prepared

Perceptions of Flooding Amount, Hurricane Number/ Strength, and Climate Change Flood Amount

$$
\begin{aligned}
& \text { Decreased } \\
& \text { About the same } \\
& \text { Increased }
\end{aligned}
$$

$-1$

Hurricane Number

$$
\text { Decreased }
$$

About the same

1

Increased

Hurricane Strength

$$
\text { Not as strong }
$$

About as strong

Stronger

901

23.4

2034

Belief in Climate Change

Climate change is happening

$1634 \quad 42.4$




\begin{tabular}{|c|c|c|c|c|c|c|c|c|c|c|c|c|c|c|}
\hline \multirow[b]{2}{*}{ Variable } & \multicolumn{2}{|c|}{ Model 1} & \multicolumn{2}{|c|}{ Model 2} & \multicolumn{2}{|c|}{ Model 3} & \multicolumn{2}{|c|}{ Model 4} & \multicolumn{2}{|l|}{ Model 5} & \multicolumn{2}{|c|}{ Model 6} & \multicolumn{2}{|c|}{ Model 7} \\
\hline & $b$ & Z & $\mathrm{b}$ & Z & $b$ & Z & $\mathrm{b}$ & & $\mathrm{b}$ & Z & $\mathrm{b}$ & Z & $\mathrm{b}$ & Z \\
\hline \multicolumn{15}{|l|}{ Socio-Demographic } \\
\hline Age & 0.027 & 0.55 & 0.000 & -0.01 & 0.001 & 0.03 & 0.001 & & 0.054 & 1.01 & 0.030 & 0.62 & 0.000 & 0.00 \\
\hline Gender: female & -0.119 & -1.02 & 0.019 & 0.15 & -0.043 & -0.34 & $-0.053-0$ & & -0.036 & -0.29 & -0.067 & -0.59 & -0.045 & -0.37 \\
\hline Race: white [-] & -0.382 & $-2.56 * *$ & -0.394 & $-2.45^{* *}$ & -0.550 & $-3.26 * * *$ & $\begin{array}{ll}-0.506 & -3\end{array}$ & $0 * *$ & -0.454 & $-2.77 * *$ & -0.453 & $-3.06 * * *$ & -0.499 & $-3.09 * * *$ \\
\hline Education [+] & 0.253 & $3.30 * * *$ & 0.264 & $3.19 * * *$ & 0.251 & $2.94 * *$ & 0.2723. & $6 * * *$ & 0.212 & $2.65 * *$ & 0.219 & $6.89 * *$ & 0.258 & $3.16 * * *$ \\
\hline Income $[+]$ & 0.193 & $5.91 * * *$ & 0.215 & $6.20 * * *$ & 0.200 & $5.61 * * *$ & 0.196 & $1 * * *$ & 0.229 & $6.63 * * *$ & 0.253 & $3.38 * * *$ & 0.211 & $6.12 * * *$ \\
\hline \multicolumn{15}{|l|}{ Political orientation } \\
\hline Partisanship & 0.014 & 0.17 & -0.049 & -0.59 & 0.000 & 0.00 & 0.009 & 10 & -0.092 & -1.12 & -0.069 & -0.91 & -0.009 & -0.11 \\
\hline \multicolumn{15}{|l|}{ Home ownership } \\
\hline Owner [+] & 1.011 & $2.60 * *$ & 1.078 & $2.35^{* *}$ & 0.946 & $1.84^{*}$ & 0.924 & 79* & 0.525 & 1.32 & 0.734 & $2.02 *$ & 1.046 & $2.15^{*}$ \\
\hline Renter $[-]$ & -0.134 & -0.31 & -0.115 & -0.23 & -0.190 & -0.34 & -0.225 & 40 & -0.769 & $-1.67 *$ & -0.461 & -1.14 & -0.222 & -0.42 \\
\hline \multicolumn{15}{|c|}{ (Control group: Something else) } \\
\hline Distance from the coast [-] & -0.258 & $-7.05 * * *$ & -0.273 & $-7.02 * * *$ & -0.292 & $-6.71 * * *$ & -0.290 & $82 * * *$ & -0.295 & $-6.99 * * *$ & -0.269 & $-6.99 * * *$ & $-0.277-$ & $-6.93 * * *$ \\
\hline Trust in local government [+] & 0.103 & $1.79 *$ & 0.092 & 1.50 & 1.43 & 0.065 & 0.072 & 14 & 0.096 & 1.57 & 0.087 & 1.55 & 0.082 & 1.35 \\
\hline \multicolumn{15}{|l|}{ Perceptions } \\
\hline Flooding amount [+] & 0.174 & $1.83^{*}$ & & & & & & & & & & & & \\
\hline Hurricane number $[+]$ & 0.087 & 0.92 & & & & & & & & & & & & \\
\hline Hurricane strength $[+]$ & 0.180 & $1.95^{*}$ & & & & & & & & & & & & \\
\hline Belief in climate change $[+]$ & 0.127 & 0.86 & & & & & & & & & & & & \\
\hline \multicolumn{15}{|l|}{ Objective conditions } \\
\hline Storm surge $[+]$ & & & 0.019 & $2.14^{*}$ & & & & & & & & & & \\
\hline \multicolumn{5}{|c|}{ Percentage of 100 -year flood zone per county [+] } & 1.136 & $2.87^{* *}$ & & & & & & & & \\
\hline \multirow{2}{*}{\multicolumn{5}{|c|}{$\begin{array}{l}\text { Percentage of } 100 \text {-year flood zone (high risk) per county }[+] \\
\text { Maximum property damage from flooding in the last } 10 \text { years }[+]\end{array}$}} & & & 1.145 & $2.01 *$ & & & & & & \\
\hline & & & & & & & & & 0.000 & 1.58 & & & & \\
\hline \multicolumn{5}{|c|}{ Property damage from the latest flooding $[+]$} & & & & & & & -0.000 & -0.66 & & \\
\hline \multicolumn{5}{|c|}{ County average premium [-] } & & & & & & & & & -0.000 & -0.12 \\
\hline Random intercept & estimate & SE & estimate & SE & estimate & SE & estimate & SE & estimate & SE & estimate & SE & estimate & SE \\
\hline State & 0.273 & 0.185 & 0.186 & 0.134 & 0.121 & 0.097 & 0.139 & 0.108 & 0.275 & 0.202 & 0.326 & 0.232 & 0.234 & 0.167 \\
\hline County & & & 0.000 & 0.000 & 0.027 & 0.048 & 0.026 & 0.046 & 0.188 & 0.095 & 0.172 & 0.088 & 0.043 & 0.057 \\
\hline$p(L R)$ & & 000 & 0.0 & & & 0.0000 & & 000 & 0.00 & 000 & 0.00 & 000 & 0.00 & 000 \\
\hline $\mathbf{N}$ & & & 144 & & & 428 & & 428 & & 538 & 180 & 305 & 153 & 31 \\
\hline
\end{tabular}


Table III. Models of totally and partially voluntary flood insurance behavior

\begin{tabular}{|c|c|c|c|c|c|c|c|c|c|c|c|c|c|c|}
\hline \multirow[b]{2}{*}{ Variable } & \multicolumn{2}{|l|}{ Model 1} & \multicolumn{2}{|c|}{ Model 2} & \multicolumn{2}{|c|}{ Model 3} & \multicolumn{2}{|l|}{ Model 4} & \multicolumn{2}{|l|}{ Model 5} & \multicolumn{2}{|c|}{ Model 6} & \multicolumn{2}{|c|}{ Model 7} \\
\hline & $\mathrm{b}$ & Z & $b$ & Z & $b$ & Z & $b$ & & $\mathrm{~b}$ & Z & $\mathrm{b}$ & Z & $b$ & Z \\
\hline \multicolumn{15}{|l|}{ Socio-Demographic } \\
\hline Age & 0.030 & 0.69 & -0.018 & -0.36 & $-0.011-c$ & -0.22 & -0.012 & -0.24 & 0.046 & 0.94 & 0.016 & 0.37 & -0.018 & -0.38 \\
\hline Gender: female & 0.006 & 0.05 & 0.089 & 0.78 & $0.034 \quad 0$ & 0.29 & 0.035 & 0.30 & 0.082 & 0.72 & 0.056 & 0.54 & 0.044 & 0.39 \\
\hline Race: white [-] & -0.384 & $-2.87 * *$ & -0.430 & $-2.88^{* *}$ & -0.484 & $-3.10 * * *$ & $\begin{array}{ll}-0.482 & -3 .\end{array}$ & $-3.10 * *$ & -0.462 & $-3.07 * * *$ & -0.448 & $-3.30 * * *$ & -0.488 & $-3.29 * * *$ \\
\hline Education [+] & 0.166 & $2.49 * *$ & 0.170 & $2.31 *$ & 0.201 & $2.63 * *$ & $0.206 \quad 2$ & $2.70 * *$ & 0.151 & $2.11^{*}$ & 0.158 & $2.39 * *$ & 0.175 & $2.40 * *$ \\
\hline Income $[+]$ & 0.182 & $6.32 * * *$ & 0.214 & $6.77 * * *$ & 0.187 & $5.79 * * *$ & 0.189 & $5.87 * * *$ & 0.221 & $7.06^{* * *}$ & 0.216 & $7.52 * * *$ & 0.203 & $6.54 * * *$ \\
\hline \multicolumn{15}{|l|}{ Political orientation } \\
\hline Partisanship & -0.034 & -0.47 & -0.068 & -0.89 & -0.034 & -0.44 & -0.029 & -0.38 & -0.124 & -1.65 & -0.102 & -1.48 & -0.037 & -0.49 \\
\hline \multicolumn{15}{|l|}{ Home ownership } \\
\hline Owner [+] & 0.913 & $2.84 * *$ & 0.896 & $2.39 * *$ & 0.738 & $1.77^{*}$ & 0.743 & $1.77^{*}$ & 0.673 & $1.86^{*}$ & 0.778 & $2.45^{* *}$ & 0.912 & $2.29 *$ \\
\hline Renter $[-]$ & -0.291 & -0.82 & -0.314 & -0.76 & -0.419 & -0.92 & -0.422 & .92 & -0.802 & $-1.92^{*}$ & -0.481 & -1.36 & -0.387 & -0.89 \\
\hline (Control group: Something & gelse) & & & & & & & & & & & & & \\
\hline Distance from the coast [-] & -0.283 & $-8.63 * * *$ & -0.309 & $-8.00 * * *$ & -0.292 & $-6.71 * * *$ & -0.342 & $48^{* * *}$ & -0.320 & $-8.18 * * *$ & -0.306 & $-8.58 * * *$ & -0.315 & $-8.33 * * *$ \\
\hline Trust in local government [+ & [+] 0.111 & $2.10^{*}$ & 0.080 & 1.40 & 1.43 & 0.065 & 0.060 & .03 & 0.104 & $1.85^{*}$ & 0.085 & $1.64 *$ & 0.068 & 1.21 \\
\hline Perceptions & & & & & & & & & & & & & & \\
\hline Flooding amount [+] & 0.171 & $2.02 *$ & & & & & & & & & & & & \\
\hline Hurricane number [+] & 0.046 & 0.54 & & & & & & & & & & & & \\
\hline Hurricane strength $[+]$ & 0.183 & $2.21 *$ & & & & & & & & & & & & \\
\hline Belief in climate change $[+]$ & 0.170 & 1.26 & & & & & & & & & & & & \\
\hline Objective conditions & & & & & & & & & & & & & & \\
\hline Storm surge $[+]$ & & & 0.021 & 1.63 & & & & & & & & & & \\
\hline Percentage of 100 -year floo & od zone pe & er county $[-$ & & & 1.136 & $2.87 * *$ & & & & & & & & \\
\hline Percentage of 100 -year floo & od zone (hi & high risk) pe & er county [ & & & & 1.594 & $2.86 * *$ & & & & & & \\
\hline Maximum property damage & se from floo & boding in th & he last $10 \mathrm{y}$ & years [+] & & & & & 0.000 & 1.31 & & & & \\
\hline Property damage from the & latest floo & oding [+] & & & & & & & & & -0.000 & -0.58 & & \\
\hline County average premium [- & & & & & & & & & & & & & 0.000 & 0.54 \\
\hline Random intercept & estimate & SE & estimat & SE & estimate & SE & estimate & SE & estimate & SE & estimate & SE & estimate & $\mathrm{SE}$ \\
\hline State & 0.387 & 0.254 & 0.292 & 0.216 & 0.196 & 0.152 & 0.202 & 0.149 & 0.375 & 0.272 & 0.437 & 0.308 & 0.354 & 0.251 \\
\hline County & & & 0.130 & 0.087 & 0.090 & 0.072 & 0.057 & 0.057 & 0.299 & 0.112 & 0.279 & 0.102 & 0.138 & 0.083 \\
\hline$p(L R)$ & & 0000 & & 0.0000 & & 0.0000 & & 000 & 0.0 & 000 & 0.00 & & 0.00 & 00 \\
\hline $\begin{array}{l}\mathrm{N} \\
\end{array}$ & 164 & 545 & & 1671 & & 1620 & & 620 & & 779 & 209 & & 175 & \\
\hline
\end{tabular}

${ }^{*} \mathrm{p}<0.05 ; * * \mathrm{p}<0.01 ; * * \mathrm{p}<0.001$ 


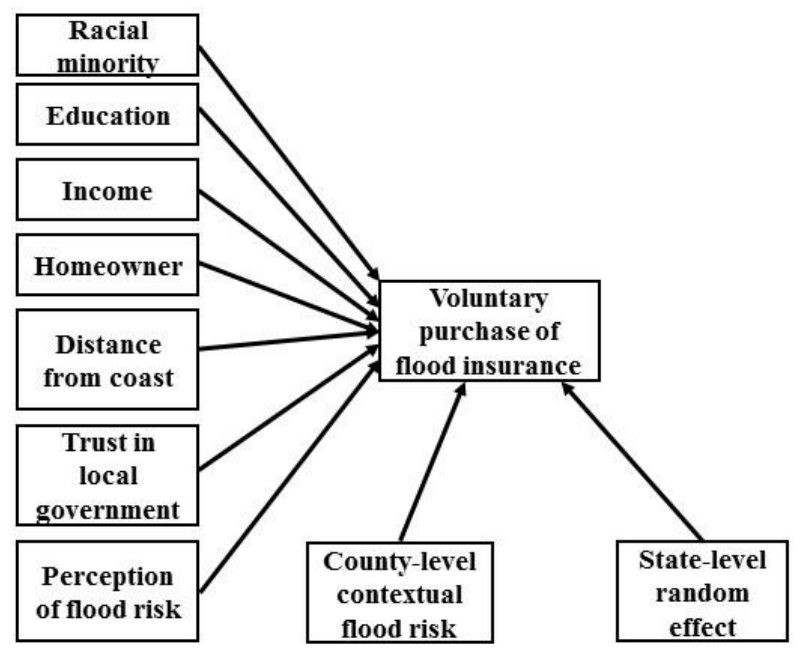

First level (individual) Second level (county) Third level (state)

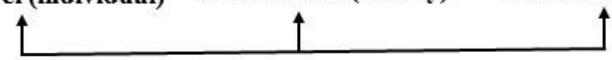

Multilevel Modeling 